\title{
Effects of Different Feeding Regimes on Growth Performance and Intestinal Morphology of \\ Commercial Broilers
}

http://dx.doi.org/10.1590/1806-9061-2021-1523

Original Article

\section{-Author(s)}

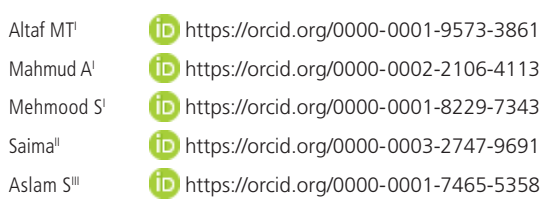

Department of Poultry Production, Faculty of Animal Production and Technology, University of Veterinary and Animal Sciences, Lahore 54000, Pakistan

" Department of Animal Nutrition, Faculty of Animal Production and Technology, University of Veterinary and Animal Sciences, Lahore 54000, Pakistan

III Department of Veterinary Surgery and Pet Sciences, Faculty of Veterinary Science, University of Veterinary and Animal Sciences, Lahore 54000, Pakistan

\section{nail Address}

Corresponding author e-mail address Athar Mahmud

Department of Poultry Production, Faculty of Animal Production and Technology,

University of Veterinary and Animal

Sciences, Lahore-Pakistan.

Phone: +92-300-8845733

Email: atharmahmud@uvas.edu.pk

\section{nKeywords}

Broiler, phases, synbiotics level, growth performance, intestinal morphology.

\section{ABSTRACT}

The present study aimed to evaluate the influence of various levels of synbiotics on growth performance and intestinal morphology of fast-growing broilers during different phases. A total of 720 , oneday-old straight run broilers (Ross 308) were randomly divided into 12 treatment groups according to a completely randomized design having three supplemented diets of synbiotics (a combination of probiotics and prebiotics) $(0.5,1$, and $1.5 \%)$ reared at four phases [starter (1-11 days), grower (12-22 days), finisher (23-35 days), whole life (1-35 days)]. Every treatment was replicated six times with ten birds each. The parameters were evaluated in growth performance (feed intake, body weight, feed conversion ratio, and mortality) and intestinal morphology (Villus height, Crypt depth and Villus to Crypt ratio). Results of the present study revealed that growth performance, feed intake $(p=0.0029)$, body weight ( $p=0.0001)$ and feed conversion ratio ( $p=0.0001)$ were improved with 1 percent synbiotics diet supplementation,while1.5 percent synbiotics level showed lower body weight. Crypt death $(p=0.0529)$ has been marginally greater in the whole life. It can be inferred that a 1 $\%$ synbiotics supplemented diet has had a beneficial impact on growth and gut health throughout life.

\section{INTRODUCTION}

Poultry production, especially broiler farming is the fastest source to provide high-quality meat and nutrients like protein for the human body. Those birds fed on the commercial poultry feed can be exposed to extensive variation throughout the gastrointestinal tract (Manafi et al. 2017). Beneficial bacteria play an important role in the intestinal tract, which ultimately affects the performance of the birds because those bacteria enhance the nutrients absorption, gut morphology, and immune response (Lee et al., 2002). The beneficial synthetic bacteria are available in the form of probiotics and prebiotics and also synbiotics that are supplemented in broiler feed to increase feed efficiency and minimize the cost of production (Sarangi et al., 2016). These growth promoters like synbiotics are in practice for many decades to control disease threat (Akinleye et al., 2008). However, the long use of antibiotics in broilers rearing can impart residues in meat. Some scientists found various feed additives like prebiotic, probiotic, and synbiotics as alternate antibiotics in poultry nutrition (Patterson \& Burkholder, 2003). The specific feed additive like synbiotics is used nowadays to improve gut activity, enhance the immune system (Hamasalim, 2016), reduce $\mathrm{pH}$, maximize the digestibility of the nutrients, and also to increase the protective gut mucus (Nikpiran et al., 2014). Intestines play an important role in the digestion and absorption of nutrients to maintain proper body functions. The spreading of pathogens throughout the intestines 
often results in inflammation that is the source of production loss, a higher percentage of mortality, and also contaminates poultry products (Baurhoo et al., 2009). The supplementation of synbiotics in feed minimizes the colonies of intestinal salmonella, E. coli, and other harmful bacteria (Baurhoo et al., 2007a). It also increases the goblet cell number of the intestinal villi which increases the nutrient absorption in the small intestine (Baurhoo et al., 2007b).

The addition of synbiotics or other growth promoters in the broiler diet improved villus height gradually at 35 days of age. The increase in the surface area of the villus in the bird's small intestine during the $1 \mathrm{st}, 3 \mathrm{rd}$, and 5th weeks resulted in increased growth performance and carcass yield in broilers (Miles et al., 2006). Although, the data regarding supplementation of synbiotics in poultry feed is abundant, information regarding its addition at different phases of broiler life is scarce. Keeping this in view, the present study was planned to evaluate the effect of different synbiotics levels on growth performance and histological parameters during different stages of life in broilers.

Pakistan is a developing country where poultry industry is the second largest growing enterprise providing employment opportunities to more than 1.5 million people. However, there is a big space for the poultry producers from Pakistan to capture the international market. To meet the demand of local market and to fulfil the criteria of European and other developed countries, producers must meet the antibiotic free production of poultry. Pakistan Poultry Industry is trying hard to boost the business by exporting the poultry products. However, the usage of antibiotics, little space provided to the birds during rearing and lack of knowledge about the dose rate of antibiotics' alternatives are the major hurdles in this regard.

Therefore, the present study was conducted to evaluate the effect of various levels of synbiotics and their effect on growth performance and intestinal morphology of commercial broilers reared under different life phases.

\section{MATERIALS AND METHODS}

This trial was conducted at the Poultry Research and Training Centre, the University of Veterinary and Animal Sciences, Ravi Campus, Pattoki, Pakistan. A total of 720, one-day-old straight-run broilers (Ross308) were obtained from a commercial hatchery and assigned to 12 treatment groups consisting of 3 levels of synbiotics during 4 phases of life. A $3 \times 4$ factorial arrangement of treatments followed a Completely Randomized Design. Three different levels of synbiotics were offered during various growth phases including starter (1-10 days), grower (11-22 days), finisher (2335 days), and the whole life period (1 to 35 days). The chicks were divided randomly into 12 treatment groups having 6 replicates of 10 chicks each. The supplemented feed was offered to the birds according to the phases during the whole study (Table 1). For ad libitum feeding and clean, fresh drinking water, each replicate $\left(1 \times 1 \mathrm{~m}^{2}\right.$ floor density) was equipped with one round feeder and a nipple drinker. For the first week after hatching, brooding temperature and relative humidity $(\mathrm{RH})$ washeld at $34 \pm 1{ }^{\circ} \mathrm{C}$ and 62 \pm 3 percent, respectively. After that, the temperature was steadily decreased until it reached $24{ }^{\circ} \mathrm{C}$ on day 21 with $\mathrm{RH} 65 \%$. A lighting program of $23 \mathrm{~L}: 1 \mathrm{D}$ was implemented throughout the study.

Table 1 - Calculated composition of the basal diet components and nutrients.

\begin{tabular}{lccc}
\hline \multirow{2}{*}{ Ingredient } & \multicolumn{3}{c}{ Inclusion level (\%) } \\
\cline { 2 - 4 } & Starter & Grower & Finisher \\
\hline Corn 12 & 58.62 & 60.29 & 60.88 \\
Soybean Meal 45 & 28.82 & 25.86 & 20.13 \\
Rice Polish 17 & 4.00 & 4.00 & 5.50 \\
Fish Meal 48 & 3.00 & 4.00 & 4.19 \\
Soy Oil & 1.67 & 2.81 & 4.00 \\
Canola & ---- & ---- & 3.00 \\
Calcium CO3 & 1.23 & 1.10 & 0.92 \\
Mono Calcium Phosphate & 0.82 & 0.49 & 0.18 \\
L-Lysine SO4 & 0.62 & 0.47 & 0.37 \\
DL-Methionine & 0.39 & 0.32 & 0.25 \\
Common Salt & 0.29 & 0.27 & 0.22 \\
Threonine & 0.22 & 0.15 & 0.15 \\
Vitamin Mineral Premix & 0.15 & 0.15 & 0.15 \\
L-Argnine & 0.14 & 0.07 & 0.04 \\
Winzyme HTR & 0.01 & 0.01 & 0.01 \\
Total & 100 & 100 & 100 \\
\hline
\end{tabular}

\section{Parameters evaluated}

\section{Growth performance}

The data were collected regarding the growth performance of the broilers including feed intake (g), body weight (g), and feed conversion ratio (FCR). Bodyweight and feed intake were recorded every week from each treatment group for the entire 35 days of the experiment. The body weight gain was calculated by subtracting the initial body weight from the final body weight. The feed conversion ratio was also recorded by dividing feed intake over body weight gain (Ghasemi et al., 2016). 


\section{Intestinal morphology}

On the 35th day, 3 birds per replicate were randomly picked up and slaughtered by the halal method (Altaf et al., 2019). lleum samples were obtained for intestinal morphology to determine the height of the villus $(\mu \mathrm{m})$, crypt depth $(\mu \mathrm{m})$, andthe ratio of the villus to crypt (Giannenas et al.,2012).

\section{Statistical Analysis}

The collected data were analyzed using PROC GLM in SAS software 9.1over a factorial ANOVA. For comparison of significant treatment means, Duncan's Multiple Range (DMR) test (Duncan, 1955) was applied. The following mathematical model was used:

$Y_{i j k}=\mu+\alpha_{i}+\beta_{j}+(\alpha \beta)_{i j}+\varepsilon_{i j k}$

Where,

$Y_{i j k}=$ Observation of dependent variables recorded on $\mathrm{ith}^{\text {th }}$ and $\mathrm{j}^{\text {th }}$ treatment groups

$\mu=$ Population mean

$\alpha_{i}=$ Effect of $i^{\text {th }}$ synbiotics level $(i=1,2,3)$

$\beta_{i}=$ Effect of $j^{\text {th }}$ phase feeding $(j=1,2,3,4)$

$(\alpha \beta)_{i j}=$ Interaction effects of $i^{\text {th }}$ and $j^{\text {th }}$ treatment group

$\varepsilon_{i \mathrm{ijk}}=$ Residual effect associated with $i^{\text {th }}$ and $j^{\text {th }}$ treatment group, NID $\sim 0, \sigma^{2}$

\section{RESULTS AND DISCUSSION}

\section{Growth performance}

\section{Feed Intake}

Means of both treatments (Phases and levels of Synbiotics) individually and in interaction demonstrated differences in feed consumption (Table 3). The highest feed consumption was observed fed at 1.5 percent synbiotic levels, while the lowest $(p=0.0029)$ feed consumption at 0.5 percent level in the diet. The increase in feed intake in broilers could perhaps be due to the addition of synbiotics enhancing function of gastric juice thus increasing the utility of the nutrients in the intestine. Similarly, Samli et al. (2007) reported that feed intake was improved with the addition of synbiotics in the diet. Sarangi etal. (2016) have observed substantially higher feed consumption in birds when supplemented with a diet fed with synbiotics.

As far as the different phases are concerned, no major variations in feed consumption have been found between all treatment groups. The relationship between levels and phases of synbiotics showed differences in feed intake. During the growing phase, the birds fed at a 1.5 percent level of dietary synbiotics reported the highest feed consumption, while the lowest was found in birds fed 1 percent of synbiotics level.

Table 2 - Schedule of Vaccination for experimental birds.

\begin{tabular}{lcc}
\hline Days & Vaccines & Routes \\
1 & $\mathrm{ND}+\mathrm{IB}$ & Eye Drop \\
5 & $\mathrm{ND}+\mathrm{IB}$ & Eye Drop \\
12 & $\mathrm{IBD}$ & Spray \\
19 & $\mathrm{ND}+\mathrm{IB}$ & Drinking water \\
\hline
\end{tabular}

$\mathrm{ND}=$ Newcastle Disease; $\mid \mathrm{B}=$ Infectious Bronchitis; $\mathrm{IBD}=$ Infectious Bursal Disease

\section{Bodyweight}

Different treatments have shown a pronounced effect on the bodyweight including different phases and levels of synbiotics and their interaction (Table 3). Synbiotics showed the highest body weight at a 1 percent inclusion level, while supplementation with 0.5 percent synbiotics showed the lowest body weight. The beneficial properties of synbiotics, which promote the growth of one or a small number of bacteria in the colon, raising the host's health and body weight, may be the reason for the increased body weight (Ashayerizadeh et al., 2009). Supplementation with synbiotics at a 1 percent diet stage greatly raises body weight in broilers (Erdoğan et al., 2010).

As far as the different phases are concerned, no major differences were found between all treatment groups in body weight. There was a difference in body weight in the interaction between synbiotics levels and phases. The birds fed at a 1 percent level of synbiotics in the diet showed the highest body weight throughout the whole life cycle, whereas the lowest was observed in birds fed 0.5 percent synbiotics level in the grower phase. The supplemented diet of synbiotics found significantly higher body weight in broilers over the entire life cycle (Samli et al., 2007).

\section{Feed Conversion Ratio}

There were major differences between the different treatment groups in the overall feed conversion ratio (FCR) (Table 3). The birds fed 1 percent of synbiotics showed improved FCR compared to the others. Feed conversion ratio may improve the intestinal environment as dietary synbiotics feeding reduces intestinal $\mathrm{pH}$ and increases the activity of digestive enzymes produced in the gut (Samli et al., 2007). Abdul-Raheem and AbdAllah. (2011) indicated improvement of the final body weight of synbiotics supplemented broilers compared to the prebiotic groups. In the present study, the better FCR in synbiotics supplemented birds might be due to the increased nutrient absorption which might have 
Table 3 - Effects of various levels of synbiotics on growth performance and intestinal morphology (mean \pm standard errors) of broiler chickens raised during different phases.

\begin{tabular}{llccccccc}
\hline Treatment & & $\mathrm{Fl}$ & $\mathrm{BW}$ & $\mathrm{FCR}$ & $\mathrm{MOR}$ & $\mathrm{VH}$ & $\mathrm{CD}$ & $\mathrm{V}: \mathrm{C}$ \\
\hline \multirow{3}{*}{ Phases } & Starter & 3671.78 & 2209.26 & 1.67 & 9.67 & 827.24 & $209.99^{\mathrm{a}}$ & 4.05 \\
& Grower & 3705.33 & 2216.39 & 1.68 & 10.22 & 713.79 & $151.75^{\mathrm{b}}$ & 4.7 \\
& Finisher & 3749.44 & 2225.57 & 1.69 & 7.8 & 634.86 & $167.16^{\mathrm{ab}}$ & 3.75 \\
W-value & Whole life & 3799.44 & 2261.27 & 1.69 & 7.22 & 699.93 & $150.89^{\mathrm{b}}$ & 4.61 \\
& & 0.261 & 0.6593 & 0.9771 & 0.98 & 0.5485 & 0.0524 & 0.3911 \\
Synbiotic levels (\%) & 1 & $3730.08^{\mathrm{ab}}$ & $2106.97^{\mathrm{b}}$ & $1.77^{\mathrm{a}}$ & 5.01 & 737.19 & 173.67 & 4.26 \\
& 1.5 & $3621.83^{\mathrm{b}}$ & $2384.44^{\mathrm{a}}$ & $1.52^{\mathrm{b}}$ & 7.33 & 689.82 & 179.01 & 3.73 \\
p-value & 1.5 & $3842.58^{\mathrm{a}}$ & $2192.97^{\mathrm{b}}$ & $1.76^{\mathrm{a}}$ & 4.85 & 729.86 & 157.16 & 4.84 \\
SEM & & 0.0029 & 0.0001 & 0.0001 & 0.5201 & 0.9061 & 0.5402 & 0.1488 \\
\hline
\end{tabular}

Superscripts on different means within column differ significantly at $p \leq 0.05$.

$\mathrm{FI}=$ feed intake (g); BW = body weight (g); FCR = feed conversion ratio; MOR = mortality (\%); VH = villus height $(\mu \mathrm{m}) ; \mathrm{CD}=\mathrm{crypt}$ death $(\mu \mathrm{m}) ; \mathrm{V}: \mathrm{C}=$ villus height to crypt depth ratio.

influenced the overall efficiency of the diet and bird's weight. Khalaji et al. (2010) investigated the effect of iso-Malto oligosaccharide (IMO) in concentrations of 1 , 2 , and $4 \%$, but found no differences in feed efficiency and FCR. Feed conversion rate (FCR) was observed to be significantly better in birds when supplementation with synbiotics was offered (Awad et al., 2009). Similarly, Mountzouris et al. (2007) reported that FCR was improved with the addition of synbiotics in the diet.

As far as the different phases are concerned, there were no major differences in FCR between all treatment groups. The interaction between synbiotics levels and phases showed a variation in feed conversion ratio. The birds fed at a $1 \%$ level of synbiotics in the diet during the whole life phase showed the best FCR, whereas, the lowest was observed in the birds fed synbiotics level of $0.5 \%$ in the finisher phase. Dizaji et al. (2012) found significantly better FCR during the whole life phase when fed with synbiotics in the diet.

\section{Mortality}

Means of mortality percentage did not differ in the phases, various levels of synbiotics, and their interaction among all treatment groups ( $p>0.05)$.

\section{Intestinal morphology}

\section{Villus height}

Means of various phases and levels of synbiotics were reported non-significant in villus height (Table 4). In 1 percent of synbiotics supplemented groups raised during the entire life period, the contact between different treatment groups showed higher villus height, while the lowest was found in $0.5 \%$ of the synbiotics supplemented group during the whole life.

\section{Crypt Ratio}

Histological parameters differed among different levels of synbiotics, phases, and their interaction (Table 4). Crypt depth was better during the entire life phases compared to others. Significant interactions were observed regarding the villus height, crypt depth, and villus to crypt ratio. The addition of synbiotics in the diet has been reported to influence epithelial cells thereby increasing the number of cells present in the villi. Therefore, the surface area of the villus is increased which also maximizes nutrients digestion (Awad et al.,2008). The reduction in the height of the villus in the surface region and the rise in the thickness of the crypt depth leads to a decrease in the absorption of nutrients in the small intestine that eventually affects the production of the birds (Xu et al., 2003). The shortening of the crypt depth is beneficial for nutrient absorption in the gut. Synbiotics can influence deeper crypt tissues which are the source to inhibit the crypt cell renewal and also the regeneration of the villus cells if needed (Giannenas et al.,2012).

\section{Villus to Crypt Ratio}

No major variations were found between the total means of the phases and synbiotics levels (Table 3). The ratio between villus and crypt was raised during the finisher phase in the interaction 1 percent level of synbiotics supplemented group, while 0.5 percent synbiotics level showed the lowest growing phase values. The addition of synbiotics in the broiler diet was found to significantly improve villus to crypt ratio; these improvements indicate better nutrient absorption throughout the small intestine of the birds (Shokri et al., 2017). Hassanpour et al. (2013) also found the maximum values of intestinal morphology with added diet insynbiotics at $1 \mathrm{~g} / \mathrm{kg}$. The increasedratio of the 
Table 4 - Interaction effects of phases and levels of synbiotics on growth performance and intestinal morphology (means \pm standard errors) of broilers.

\begin{tabular}{|c|c|c|c|c|c|c|c|c|}
\hline Treatment & & $\mathrm{FI}$ & BW & FCR & MOR & $\mathrm{VH}$ & $C D$ & $\mathrm{~V}: \mathrm{C}$ \\
\hline \multirow{3}{*}{ Starter } & 0.5 & 3625.6 & $2095.14^{\mathrm{ab}}$ & $1.73^{\mathrm{ab}}$ & 6.67 & $851.61^{\mathrm{ab}}$ & $239.45^{a}$ & $3.47^{b c}$ \\
\hline & 1 & 3605.6 & $2378.71^{a}$ & $1.52^{c}$ & 3.33 & $772.66^{a b}$ & $210.42^{\mathrm{ab}}$ & $3.71^{b c}$ \\
\hline & 1.5 & 3784.00 & $2153.94^{\mathrm{ab}}$ & $1.76^{\mathrm{a}}$ & 10.01 & $857.46^{\mathrm{ab}}$ & $180.12^{\mathrm{ab}}$ & $4.98^{\mathrm{abc}}$ \\
\hline \multirow{3}{*}{ Grower } & 0.5 & 3670.67 & $2044.07 c$ & $1.79^{a}$ & 10.01 & $1000.50^{a}$ & $153.64^{\mathrm{ab}}$ & $6.58^{a}$ \\
\hline & 1 & 3565.33 & $2376.62^{\mathrm{a}}$ & $1.51^{\mathrm{bc}}$ & 6.67 & $627.86^{\mathrm{ab}}$ & $174.28^{\mathrm{ab}}$ & $3.42^{\mathrm{bc}}$ \\
\hline & 1.5 & 3928.00 & $2228.47^{\mathrm{ab}}$ & $1.77^{\mathrm{a}}$ & 10.01 & $502.99^{a b}$ & $127.34^{b}$ & 4. $10^{\mathrm{abc}}$ \\
\hline \multirow{3}{*}{ Finisher } & 0.5 & 3767.00 & $2145.38^{\mathrm{ab}}$ & $1.76^{\mathrm{a}}$ & 13.33 & $729.97^{\mathrm{ab}}$ & $176.66^{\mathrm{ab}}$ & $4.13^{a b c}$ \\
\hline & 1 & 3645.67 & $2387.27^{a}$ & $1.53^{\mathrm{bc}}$ & 10.01 & $358.38^{b}$ & $135.89^{b}$ & $2.68^{c}$ \\
\hline & 1.5 & 3835.67 & $2144.07^{\mathrm{ab}}$ & $1.79^{a}$ & 13.33 & $816.24^{\mathrm{ab}}$ & $188.92^{\mathrm{ab}}$ & $4.46^{\mathrm{abc}}$ \\
\hline \multirow{3}{*}{ Whole life } & 0.5 & 3905.00 & $2143.29^{a b}$ & $1.83^{\mathrm{a}}$ & 20.01 & $356.64^{b}$ & $124.94^{b}$ & $2.86^{b c}$ \\
\hline & 1 & 3622.6 & $2395.14^{\mathrm{a}}$ & $1.50^{c}$ & 13.33 & $1010.40^{\mathrm{a}}$ & $195.45^{\mathrm{ab}}$ & $5.12^{\mathrm{abc}}$ \\
\hline & 1.5 & 3822.67 & $2245.38^{\mathrm{ab}}$ & $1.71^{\mathrm{abc}}$ & 10.06 & $742.75^{\mathrm{ab}}$ & $132.29^{b}$ & $5.84^{\mathrm{ab}}$ \\
\hline SEM & & 27.8 & 24.27 & 0.03 & 0.85 & 52.03 & 8.62 & 0.27 \\
\hline$p$-value & & 0.0675 & 0.0453 & 0.0186 & 0.3300 & 0.0405 & 0.0497 & 0.0312 \\
\hline
\end{tabular}

Superscripts on different means within column differ significantly at $p \leq 0.05$.

$\mathrm{Fl}=$ feed intake (g); $\mathrm{BW}=$ body weight $(\mathrm{g}) ; \mathrm{FCR}=$ feed conversion ratio; $\mathrm{MOR}=$ mortality $(\%) ; \mathrm{VH}=$ villus height $(\mu \mathrm{m}) ; \mathrm{CD}=\operatorname{crypt}$ death $(\mu \mathrm{m}) ; \mathrm{V}: \mathrm{C}=$ villus height to crypt depth ratio.

villus to crypt ratio by synbiotics-fed birds may be attributed to the increase of epithelial cells in the gut (Deng et al., 2012).

\section{CONCLUSIONS}

In conclusion, supplementing various levels of dietary synbioticsand different phases of commercial broiler may boost the efficiency of growth and intestinal morphology that enhances intestinal immersion. Besides, feed at a $1 \%$ level of dietary synbiotics in birds had a positive impact on the growth efficiency and crypt depth.

\section{REFERENCES}

Abdul-Raheem SM, Abd-Allah SMS. The effect of single or combined dietary supplementation of mannanoligosacharide and probiotics on performance and slaughter characteristics of broilers. International Journal of Poultry Science 2011;10(11):854-862.

Akinleye SB, lyayi EA, Afolabi KD. The performance, haematology and carcass traits of broilers as affected by diets supplemented with or without biomin a natural growth promoter. World Journal of Agricultural Sciences 2008;4(4):467-470.

Altaf MT, Mahmud A, Mehmood S, Saima. Effects of supplemented growth promoters on performance and intestinal morphology in broilers reared under different stocking densities. Brazilian Journal of Poultry Science 2019;21(4):001-006

Awad W, Ghareeb K, Böhm J. Intestinal structure and function of broiler chickens on diets supplemented with a synbiotic containing Enterococcus faeciumand oligosaccha-rides. International Journal of Molecular Science 2008:9:2205-2216.

Awad WA, Ghareeb K, Abdel-Raheem S, Böhm J. Effects of dietary inclusion of probiotic and synbiotic on growth performance, organ weights, and intestinal histomorphology of broiler chickens. Poultry Science 2009;88:49-55.
Baurhoo B, Ferket PR, Zhao X. Effects of diets containing different concentrations of mannanoligosaccharide or antibiotics on growth performance, intestinal development, cecal and litter microbial populations, and carcass parameters of broilers. Poultry Science 2009;88:2262-2272.

Baurhoo B, Letellier A, Zhao X, Ruiz-Feria CA. Cecal populations of lactobacilli and bifidobacteria and Escherichia colipopulations after in vivo Escherichia colichallenge in birds fed diets with purified lignin or mannanoligosaccharides. Poultry Science 2007a;86:2509-2516.

Baurhoo B, Phillip L, Ruiz-Feria CA. Effects of purified lignin and mannan oligosaccharides on intestinal integrity and microbial populations in the ceca and litter of broiler chickens. Poultry Science 2007b;86:10701078.

Deng W, Dong XF, Tong JM, Zhang Q. The probiotic Bacillus licheniformis ameliorates heat stress-induced impair-ment of egg production, gut morphology, and intestinal mucosal immunity in laying hens. Poultry Science 2012;91:575-582.

Dizaji BR, Hejazi S, Zakeri A. Effects of dietary supplementations of prebiotics, probiotics, synbiot-ics and acidifiers on growth performance and organs weights of broiler chicken. European Journal of Experimental Biology 2012;2(6):2125-2129.

Duncan DB. Multiple range and Multiple F tests. Biometrics1955;11:1-42.

ErdoğanZ, Erdoğan S, Aslantaş Ö, Çelik S. Effects of dietary supplementation of synbiotics and phytobiotics on performance, caecal coliform population and some oxidant/antioxidant parameters of broilers. Journal of Animal Physiology and Animal Nutrition 2010;94:40-48.

Ghasemi HA, Shivazad M, Rezaei SSM, Torshizi MAK. Effect of synbiotics supplementation and dietary fat sources on broiler performance, serum lipids, muscle fatty acid profile and meat quality. British Poultry Science 2016;57:71-83.

Giannenas I, Papadopoulos E, Tsalie E, Triantafillou E, Henikl S, Teichmann $\mathrm{K}$, et al. Assessment of dietary supplementation with probiotics on performance, intestinal morphology and microflora of chickens infected with Eimeria tenella. Veterinary Parasitology 2012;188:31-40.

Hamasalim HJ. Synbiotic as feed additives relating to animal health and performance. Advancesin Microbiology 2016;6:288-302. 
Hassanpour H, Zamani Moghaddam AK, Khosravi MM. Effects of synbiotic on the intestinal morphology and hu-moral immune response in broiler chickens. Livestock Science 2013;153:116-122.

Houshmand M, Azhar K, Zulkifli I, Bejo MH, Kamyab A. Effects of nonantibiotic feed additives on performance, nutrient retention, gut $\mathrm{pH}$, and intestinal morphology of broilers fed different levels of energy. Journal of Applied Poultry Research 2011;20:121-128.

Khalaji S, Zaghari M, Nezafati VS. The effect of probiotics Tecnomoss on digestive health, safety and performance of broiler chicken. Proceedings of the 4th Iranian Animal Science Congress; 2010; Karaj, Iran. Teh-ranKaraj: Tehran University; 2010. p.207-209.

Lee MD, Lu J, Idris U, Harmon B, Hofacre C, Maurer JJ. Microbial dynamics of the broiler intestinal tract. Proceedings of the Elanco Global Enteritis Symposium; 2002; Cambridge; 2002. p.A1-A14.

Manafi M, Khalaji S, Hedayati M, Pirany N. Efficacy of Bacillus subtillis and bacitracin methylene disalicylate on growth performance, digestibility, blood metabolites, immunity, and intestinal microbiota after intramuscular inoculation with Escherichia coli in broilers. Poultry Science 2017;96(5):1174-1183.

Miles RD, Butcher GD, Henry PR, Littell RC. Effect of antibiotic growth promoters on broiler performance, intestinal growth parameters, and quantitative morphology. Poultry Science 2006;85:476-485.

Mountzouris KC, Tsistsikos P, Kalamara E, Nitsh S, Schatz-mayr G, Fegeros K. Evaluation of the efficacy of a probiotic containing Lactobacillus, Bifidobacterium, Enterococcus, and Pediococcusstrains in promoting broiler performance and modualting cecal microflora composition and metabolic activities. Poultry Science 2007;86:309-317.
Nikpiran H, Vahdatpour T, Babazadeh D, Tabatabaei SM, Vahdatpour S. Effects of functional feed additives on growth influenced hormones and performance of Japanese quails (Coturnix japonica). Greener Journalof Biological Sciences 2014;4:39-44.

Patterson JA, Burkholder KM. Application of prebiotics and probiotics in poultry production. Poultry Science 2003;82:627-631.

Samli HE, Senkoylu N, Koc F, Kanter M, Agma A. Effects of Enterococcus faeciumand dried whey on broiler performance, gut histomorphology and microbiota. Archives of Animal Nutrition 2007;61:42-49.

Sarangi NR, Babu LK, Kumar A, Pradhan CR, Pati PK, Mishra JP. Effect of dietary supplementation of prebiotic, probiotic, and synbiotics on growth performance and carcass characteristics of broiler chickens. Veterinary World 2016;9(3):313-319

Shokri AN, Hossein GA, Taherpour K. Evaluation of Aloe vera and synbiotic as antibiotic growth promoter substitutions on performance, gut morphology, immune responses and blood constitutes of broiler chickens. Animal Science Journal 2017;88:306-313.

Xu ZR, Hu CH, Xia MS, Zhan XA, Wang MQ. Effects of dietary fructooligosaccharide on digestive enzyme activities, intestinal microflora and morphology of male broilers. Poultry Science 2003;82:1030-1036 